\title{
El concepto de igualdad en la Constitución Española
}

\section{The Concept of Equality in the Spanish Constitution}

\author{
Samuel Yong Serrano *
}

Fecha de recepción: 3 de septiembre de 2008

Fecha de aprobación: 18 de septiembre de 2008

\section{Resumen}

El presente trabajo pretende revisar la forma como la doctrina y jurisprudencia española, conciben el derecho a la igualdad. Este tema que no ha sido pacífico, como se puede observar, debido a los criterios tan disímiles que existen al respecto. Así, unos le niegan el carácter de derecho, otros se lo reconocen, algunos lo consideran un principio y otros, dependiendo del escenario en el que se plantee, le otorgan la categoría de valor, principio o derecho.

\section{Palabras clave}

Igualdad, formal, material, valor, principio, derecho.

\begin{abstract}
The article pretends to review the way how spanish doctrine and jurisprudence conceives the right to equal treatment. As can be seen observed from the very different exisiting criteria, this subject has been contentious. Some people deny its character of right, others recognize it, others consider it a principle and others, depending on the context where it is presented, give it the category of value, principle and right.
\end{abstract}

\section{Key words}

Equal treatment, formal, material, value, principle, right. 


\section{INTRODUCCIÓN}

De acuerdo con la doctrina, la igualdad es uno de los fundamentos más antiguos y profundos del pensamiento liberal (Berlin, 1983, p. 178). En términos genéricos es una noción polisémica, de instrumentación difícil; es polémica, porque sus límites no son precisos, tan inaprensible que para algunos es igual de inasible como la justicia (Carmona, 1994, p. 270). Sin embargo, y a pesar de estas debilidades, no se puede desconocer que ha sido el "motor y fundamento de las sociedades democráticas actuales" (Valcárcel, 1994, p. VIII).

La idea de igualdad es filosófica e históricamente anterior al advenimiento del Estado de derecho (Baño, 1987, p. 179). Se afirma que su origen es una construcción cristiana, cuyas aplicaciones ético-políticas integran el proceso de secularización de la cultura occidental (Valcárcel, 1994, p. 2). Como esta idea requiere en su cimentación "el parámetro de un Otro" (Valcárcel, 1994, p. 2), es decir, de un factor que se convierta en necesario para valorar una situación, también se suele buscar su procedencia y desarrollo fuera del contexto religioso. Así, el término griego isonomía se asimila dentro de un contexto político, al de igualdad de los ciudadanos con respecto a las leyes, principio de equipolencia que los isónomos niegan al resto, Ios que no son ciudadanos: extranjeros, mujeres y esclavos (Valcárcel, 1994, pp. 2-3)'.

El concepto de igualdad, si bien cambia de connotación de un pensador a otro o de una sociedad a otra, para Berlin la fórmula "que cada hombre cuente por uno, y que ninguno cuente por más de uno" (Berlin, 1983, pp. 147-148), aunque vaga y ambigua, como suelen ser muchas de las más conocidas expresiones de la filosofía política, constituye el mínimo irreductible del ideal de la

1 Fernando Rey Martínez también comenta: “ $v$ de igualdad que forma parte del acervo cultural del pensamiento occidental procede de Platón y, sobre todo, de Aristóteles" (Rey, 1995, p. 40). igualdad social, que ha permeado a gran parte del pensamiento liberal y democrático. En su opinión, dicha oración categórica, muy empleada por los filósofos utilitaristas ${ }^{2}$, no depende de la creencia en derechos naturales o positivos concedidos por un poder divino o por una convención, por lo que su origen bien puede provenir de cualquier postura ideológica y, por lo tanto, adquirir validez en una sociedad ajustada al pensamiento de un Benthan como al de un Hobbes, en el cual el principio de "que cada hombre cuente por uno" se aplica estrictamente por razones utilitaristas, por deseo de la mayoría, del déspota o de quien ejerce la soberanía (Berlin, 1983, pp. 147-148).

Es importante reconocer que los más fervientes defensores de la igualdad han sido personas protectoras y promotoras del respeto a los Derechos Humanos, quienes han creído y han defendido el "principio de la igualdad a priori, revelado por la razón natural o por cualquier otra fuente o método de conocimiento" (Berlin, 1983, p. 148). Asimismo, la igualdad es concebida personas como el concepto más verdadero, sin depender de la religión, la filosofía o el ideal político que profesen. Tal fundamento fue el que sirvió de base a las declaraciones de Derechos Humanos en las revoluciones norteamericana y francesa, y que quizás constituye el principio más sólido de las doctrinas igualitaristas, desde los tiempos de los griegos hasta los socialistas y anarquistas de épocas modernas (Berlin, 1983, p. 148).

2 Para el profesor Puyol, el utilitarismo se puede definir: "como la doctrina que considera que el objetivo de la política consiste en la máximización de la utilidad o el bienestar agregado de los miembros de la sociedad. En la versión clásica de Benthan, el criterio de justicia del utilitarismo aboga por la maximización de la suma de utilidades individuales. De dicho criterio se deriva un principio de igualdad: todos los individuos cuentan por igual a la hora de sumar las utilidades, es decir, nadie resulta discriminado en el cómputo de las aportaciones individuales al bienestar colectivo. La formula más conocida de tal principio de igual consideración de los intereses de todos dice 'cada uno cuenta por uno y nadie por más de uno'" (Puyol, Ángel, 2001, pp. 28-29). 
De la fórmula igualitaria anteriormente mencionada surgió una aplicación analógica según la cual "a casos semejantes se les debe dar un tratamiento semejante" ${ }^{\prime \prime}$ que al aplicarse a sociedades humanas, dio como resultado que todos los hombres deban ser tratados de la misma manera, salvo que exista una razón suficiente para no hacerlo. Este argumento sirvió para que el principio de igualdad lograra una identidad propia, la cual se deriva de su atractivo "universal y perenne", pues no de otra manera se puede entender por qué dicha tendencia se ha incorporado a sistemas tan disímiles ideológicamente, así como se ha arraigado en el pensamiento humano hasta el punto que toda sociedad, que no da espacio suficiente a este principio, es de esa misma forma considerada menos valiosa que aquélla en la que se pretende alcanzar ese ideal igualitarista (Berlin, 1983, p. 177).

\section{POSITIVIZACIÓN Y EVOLUCIÓN JURÍDICA DEL CONCEPTO DE IGUALDAD}

\section{Igualdad formal}

El principio de igualdad se positivizó por obra del movimiento constitucional del siglo XVIII; desde un punto de vista histórico, se convirtió en un derecho de primera generación. Los documentos revolucionarios franceses fueron los que consagraron por primera vez de manera expresa el "principio de igualdad ante la ley" (Fernández, 2002, p. 57) 4, con lo que se dio una estocada final al antiguo régimen y a su sistema de inmunidades y privilegios propio de la época feudal (Carmona, 1994, p. 266).

3 Analizando esta fórmula, Hart manifiesta que: "mientras no se establezca qué semejanzas y qué diferencias son relevantes, 'tratar los casos semejantes de la misma manera' será una fórmula vacía". Para llenarla se tiene que saber cuándo, para los fines que se tienen en mira, los casos han de ser considerados iguales y qué diferencias son relevantes" (Hart, 1998, pp. 198-199).

4 En el mismo sentido se pronuncia el profesor Gálvez, quien, sin desconocer la influencia que las declaraciones americanas ejercieron en la Declaración Universal de los Derechos del Hombre y del Ciudadano, comenta que el principio moderno de igualdad hunde sus raíces en Francia, lugar donde adquirió la forma y el significado preciso $(1985$, p. 257).
Así el artículo 6o. de la Declaración de Derechos del Hombre y del Ciudadano estableció:

La ley es la expresión de la voluntad general. Todos los ciudadanos tienen derecho a participar en su elaboración, personalmente o por medio de sus representantes. La ley debe ser igual para todos, tanto para proteger como para castigar. Puesto que todos los ciudadanos son iguales ante la ley, cada cual puede aspirar a todas las dignidades, puestos y cargos públicos, según su capacidad y sin más distinción que la de sus virtudes y talentos.

Inspiradas en esta norma, las constituciones liberales posteriores incorporaron en sus textos el principio de igualdad, lo mismo hicieron los Códigos Civiles de ese tiempo (Fernández, 2002, p. 58). De esta manera, terminó el viejo régimen de privilegios y exenciones, y todos los ciudadanos quedaron sometidos al mismo régimen jurídico (Rodríguez-Piñero \& Fernández, 1986, p. 19).

En esta época, como lo señala la doctrina, el principio de igualdad ante la ley significaba "poco más que un carácter del mandato legal" (Rodríguez-Piñero \& Fernández, 1986, p. 20), pues se identificaba con la generalidad de la ley, es decir, que si todos se sometían al mismo ordenamiento jurídico, todos tenían derecho a recibir la misma protección que el ordenamiento garantizaba. Este precepto se fue afianzando con el paso del tiempo y por obra del derecho administrativo, su significado adquirió un alcance mayor, puesto que se empezó a percibir como una igualdad en la aplicación de la ley. En esta nueva concepción, ya no sólo bastaba que las leyes fueran generales o abstractas, sino que también las ramas encargadas

5 También Rubio Llorente expresa: “La obra admirable de la Revolución separa el Estado de la sociedad civil y asegura con ello la igualdad de los individuos como miembros del Estado y en su relación con él, pero no persigue asegurar la igualdad en la sociedad, que más bien niega. La ley ante la que todos los hombres son iguales es expresión de la voluntad general y, por definición, a todos los trata por igual. El principio de igualdad queda subsumido en el principio de legalidad. Son iguales aquéllos a quienes la ley considera como iguales y diferentes aquéllos a quienes diferencia" (1991, pp. 24-25). 
de aplicarlas, primero fue la ejecutiva y después el judicial, las cuales lo hicieron sin atender a consideraciones personales (Rodríguez-Piñero \& Fernández, 1986, pp. 20-21).

El principio de igualdad ante la ley se fue perfeccionando, como se puede observar en las enmiendas decimotercera a decimoquinta de la Constitución de Estados Unidos, las cuales, como resultado de la Guerra de Secesión, incluyeron por primera vez cláusulas específicas de no discriminación por razón de raza o de servidumbre (1865) (Carmona, 1994, p. 268), así como la equal protection clause (cláusula de igual protección) y la due process clause (cláusula de proceso debido), que fueron expedidas en 1868 para reforzar la Civil Rights (Ley de Derechos Civiles) de 1866 (Martín, 2003, p. 2003). Estas normas se caracterizaron por establecer límites a la potestad legislativa de la federación y sus Estados (Carmona, 1994, p. 268), de tal manera que no fueran a expedir leyes discriminatorias. Ya no sólo eran los jueces y la administración lo que debían tener en cuenta el principio de igualdad, sino que también correspondía a los legisladores hacer lo mismo.

Esta evolución del significado del concepto de igualdad, que permitía controlar el contenido de las leyes, terminó introduciéndose en Europa, al mismo tiempo que el control de constitucionalidad, comenzando por Austria y Alemania, donde se impuso a partir de la Segunda Guerra Mundial por obra de la doctrina y jurisprudencia (Fernández, 2002, p. $60)^{6}$. Anteriormente, en estos países, las normas constitucionales relacionadas con la igualdad de los ciudadanos no pasaban de ser simples declaracio-

6 Cabe anotar, que en el contexto europeo el tema de la aplicación del principio de igualdad al contenido de la ley ya se había plantado en Alemania, en la República de Weimar, cuando la doctrina dominante y la misma jurisprudencia mantuvieron una postura negativa. La misma controversia se ocasiona en Austria, donde, según la doctrina, por lo menos en los primeros treinta años, se admitió una decisión relacionada con la aplicación del principio de igualdad en el contenido de la ley (Rodríguez-Piñero \& Fernández, 1986, p. 29). nes o propósitos que no vinculaban al legislador, pero con la llegada del control de constitucionalidad sobre las leyes, consentido por las constituciones que se empezaron a expedir después de terminada la Segunda Guerra Mundial, el principio de igualdad también se comenzó a aplicar a las leyes, motivo por el cual éstas debían procurar en su forma y contenido un trato igualitario a todos los ciudadanos, so pena de ser declaradas nulas por los tribunales constitucionales (Giménez, 1999, p. 30).

Más tarde, la vinculación de la igualdad a la tarea legislativa ${ }^{7}$ se irradió desde Alemania hacia otros países, como Italia y Francia e, incluso, hacia organismos internacionales como el Tribunal Europeo de Derechos Humanos (Rodríguez-Piñero \& Fernández, 1986, pp. 30-31). De igual manera, llegó a España tras la promulgación de la Constitución de 1978 y la puesta en marcha del Tribunal Constitucional español, el cual, desde un comienzo y con apoyo en la doctrina, manifestó que el principio de igualdad vincula al legislador (Fernández, 2002, p. 60).

Esta nueva visión es la que hoy en día permite cuestionar las leyes que son discriminatorias, es decir, aquéllas que no justifican un trato desigual, sino que aplican el concepto de igualdad al contenido de la ley para hacerla exigible frente al legislador (igualdad como equiparación) (Peces-Barba, 1999, pp. 285-286). Asimismo, el legislador encuentra sus límites en el contenido de la ley y, por lo tanto, se le puede reclamar el respeto por el derecho a la igualdad, cuando teniendo la necesidad de establecer diferencias, por existir condiciones relevantes, "en relación con hechos o circunstancias personales que afectan a los contenidos de la relación jurídica", no las plasma, o cuando debiendo atribuir derechos

7 Cabe señalar que, de acuerdo con la doctrina, la evolución del concepto de igualdad es acumulativa por cuanto "una nueva dimensión de la igualdad se une, no sustituye, a las ya existentes. Por ello, pese a surgir en los últimos años la igualdad de oportunidades, la igualdad de resultados, la igualdad material, etc., [...] la igualdad formal o lo que es lo mismo, la igualdad de trato de los ciudadanos ante le ley y en la ley", sigue siendo la base del Estado de derecho (Giménez, 1999, p. 24). 
"a titulares que se encuentran en inferioridad por razones culturales, físicas o de situación", no lo hace (igualdad como diferenciación) (Peces-Barba, 1999, pp. 286-287). Se parte de la aceptación del principio de que las normas no siempre pueden tratar a todos por igual, por cuanto a veces se deben tomar en cuenta las diferencias humanas relevantes, si se quiere potenciar la igualdad ante la ley (Carmona, 1994, p. 269).

La idea de igualdad en el contenido de la ley se encuentra incluida dentro de la igualdad jurídica o igualdad ante la ley, la cual encierra dos pretensiones: la igualdad en la aplicación de las normas y la igualdad en el contenido de éstas (art. $14 \mathrm{CE}$ ) (Carmona, 1994, p. 61) ${ }^{8}$.

\section{Igualdad material}

Ahora bien, en cuanto al origen del principio de igualdad material, en lo que a Europa continental se refiere, se ubica en la Alemania de Weimar cuando el concepto de Estado social de derecho se reinterpretó. Como en toda comunidad, se existía entre sus miembros desigualdades sociales como económicas, por lo que se empezó a hablar de una igualdad material que suponía para el Estado el deber de asegurar a sus ciudadanos una igualdad que no sólo fuera de palabra, sino también real. No bastaba que el Estado se abstuviera de expedir leyes discriminatorias, sino que era su obligación adoptar las medidas necesarias para que la igualdad de las personas se hiciera efectiva (Carmona, 1994, p. 271).

Se dice que, al margen de las constituciones socialistas, la primera constitución en plasmar este tipo de igualdad fue la italiana (Carmona, 1994, p.

8 En el mismo sentido se pronuncia el profesor Ollero Tassara, quien considera que la "regla general se bifurca, pues por un lado contempla la igualdad en el trato dado por la ley, que pasa a conceptuarse como igualdad, constituyéndose un límite puesto al ejercicio del poder legislativo y de otro junto a esta exigencia surge la igualdad en la aplicación de la ley que limitará la tarea de los órganos encargados de su aplicación" (Ollero, 1989, p. 19).
272). El principal problema que plantea el principio de igualdad material es el de su eficacia jurídica (Carmona, 1994, p. 272). En la Constitución española, se consagra en el artículo 9.2.

Para el profesor Pérez Luño, desde el punto de vista de su dimensión trascendente, se infiere de la doctrina de Rousseau que el equilibrio de situaciones económicas y sociales (igualdad material) entraña un bien, un valor o un telos por conseguir a través del derecho, pues los hombres, a pesar de ser desiguales en fuerza e inteligencia, pueden llegar a ser iguales en convención y derecho. Desde esta perspectiva, la igualdad se concibe como el ideal igualitarista de la equiparación de las situaciones económicas y sociales mediante la ley (igualdad a través de la ley). Este tipo de igualdad transciende el fundamento formalista de la igualdad ante la ley que encierra la pretensión de un trato igual de los supuestos previstos en la ley, habida cuenta que ya no sólo se trata de que el contenido de la ley prohíba determinada clase de discriminación o establezca la paridad de trato en determinadas situaciones, sino que también sirva como instrumento transformador de la realidad con miras a lograr objetivos igualitarios en el ámbito social, político, económico o cultural (Pérez, 1987, p. 137).

\section{LA IGUALDAD EN LA CONSTITUCIÓN ESPAÑOLA}

De acuerdo con un sector de la doctrina, estos conceptos referidos a la igualdad están consagrados en la Constitución española en su forma más evolucionada; esto es, como valor superior, principio y derecho fundamental. Igualmente, incluye sus dos dimensiones: la igualdad formal (artículo 14) y la igualdad material (9.2) (Giménez, 1999, p. 31).

9 El profesor Díaz Revorio, luego de un análisis sobre la distinción entre un valor y un principio, llegó a la conclusión de que no debe existir entre estos dos términos una distinción tan rotunda, precisamente, porque algunos conceptos como el de la igualdad se presentan en la Constitución española como un valor (art. 1.1) y como un principio (art. 14), sin perjuicio de que éste precepto tenga una dimensión como derecho subjetivo (1997, p. 126). 


\section{La igualdad como valor}

Al lado de la libertad, la justicia y el pluralismo político, la igualdad se constituye en un valor superior del Estado social y democrático español (art. 1.1 CE) ${ }^{10}$. Su inclusión como valor superior la convierte en uno de los objetivos que el sistema jurídico político se propone alcanzar. Desde esta óptica, por ser un valor, se convierte en un fundamento principal de la interpretación constitucional (Giménez, 1999, p. 32), en especial, de los casos dudosos (Díaz, 1997, p. 45), pues en los supuestos que son claros el propio texto constitucional determina el único sentido posible del precepto.

Igualmente, desde esta perspectiva, la igualdad es una guía para orientar la evolución del ordenamiento jurídico y un criterio para medir la legitimidad de los hechos o las conductas (Giménez, 1999, p. 32) ${ }^{11}$. La positivización de valores en la Constitución genera una consecuencia, que consiste en que estos valores sean convertidos en normas jurídicas básicas a las que se deben someter los poderes públicos, por lo tanto, no constituyen un mero ideal, sino que gozan de una eficacia normativa a la que son vinculados el intérprete 0 el destinatario de los valores (Zoco, 2003, pp. 2425). En este sentido, el valor igualdad vincula a los poderes públicos de forma positiva, mandándoles actuar (Díaz, 1997, p. 214), de tal forma que impulsen la igualdad real o material y, así, aseguren la igualdad de oportunidades en la comunidad, y, de forma negativa, permitan que los actos de esos

10 Para la profesora Zoco Zabala, "Ia igualdad que propugna el artículo 1.1 CE tiene el mismo sentido que la del artículo $14 \mathrm{CE}$, aunque la eficacia jurídica de este último sea mayor; ciertamente, el mandato de igualdad en el ordenamiento jurídico español general, que propugna el artículo $1.1 \mathrm{CE}$, se proyecta singularmente en el artículo $14 \mathrm{CE}$; por ello, los artículos 14 y $1.1 \mathrm{CE}$ expresan un mismo contenido: la igualdad del ordenamiento jurídico" (Zoco, 2003, p. 37).

11 Vale la pena agregar que la igualdad, en su condición de valor superior, cumple varias funciones: es un elemento básico para fundamentar la interpretación del ordenamiento jurídico, sirve para guiar y orientar la labor hermenéutica, teleológica y evolutiva de la Constitución y, además, es un criterio para medir la legitimidad de las diversas manifestaciones del sistema de legalidad (Pérez, 1987, pp. 141-142). poderes se declaren inconstitucionales cuando son contrarios al valor de la igualdad.

El carácter de valor superior del ordenamiento jurídico ha sido afirmado por la jurisprudencia del Tribunal Constitucional en los siguientes términos:

La igualdad se configura como un valor superior que, en lo que ahora importa, se proyecta con una eficacia trascendente de modo que toda situación de desigualdad persistente a la entrada en vigor de la norma constitucional deviene incompatible con el orden de valores que la Constitución, como norma suprema, proclama (Tribunal Constitucional, STC 8/1983, FJ 3).

\section{La igualdad como principio}

Aunque no hay un acuerdo en la doctrina en cuanto a la distinción entre valores y principios constitucionales ${ }^{12}$, e incluso algunos han puesto de relieve las semejanzas entre principios y valores (Díaz, 1997, p. 109), es claro que en la Constitución española la igualdad se encuentra consagrada como valor en el artículo 1.1 y como principio en los artículos $14^{13}$ (igualdad formal) y 9.2 (igualdad material).

En su dimensión de principio, la Constitución española da a la igualdad un carácter formal cuando determina que los españoles son iguales ante la ley (art.14) (Pérez, 1987, p. 140) ${ }^{14}$. Asimismo, le

12 Así, unos los distinguen señalando el mayor contenido ético de los valores frente al contenido político que poseen los principios. Otros los distinguen desde el punto de vista de su eficacia, por lo que señalan que los valores carecen de alcance jurídico, al paso que los principios sí lo tienen. Otros, los diferencian estimando que los valores son superiores a los principios. Otros consideran que los principios entrañan un grado mayor de concreción y especificación que los valores. Otros, como Alexy, defienden que los principios pertenecen al ámbito de lo deontológico, mientras que los valores se incluyen en el nivel axiológico (Díaz, 1997, pp. 103-107).

13 Para Díaz Reborio, la igualdad también ha sido utilizada por el Tribunal Constitucional como valor y como principio, pero aquí la diferencia es más clara, por cuanto el enunciado como valor se encuentra en distinto precepto constitucional (artículo 1.1), que su formulación como principio (artículo 14) (Díaz, 1997, pp. 111).

14 El profesor Martín Cubas no parece compartir esta posición, ya que considera que la distinción entre igualdad formal y material puede ser insuficiente y cuando no, errónea. Para él, se debe buscar otra tipología de la igualdad que presente unas características más acordes con el estudio del modelo de democracia constitucional 
otorga un carácter material cuando le asigna a los poderes públicos la función de:

promover las condiciones para que la libertad y la igualdad del individuo y de los grupos en que se integra sean reales y efectivas; remover los obstáculos que impidan o dificulten su plenitud y facilitar la participación de todos los ciudadanos en la vida política, económica, cultural y social (art. 9).

\section{La igualdad formal}

De acuerdo con el Tribunal Constitucional, el principio de igualdad garantizado en el artículo 14 de la Constitución opera

[...] en dos planos distintos. De una parte, frente al legislador, o frente al poder reglamentario, impidiendo que uno u otro puedan configurar los supuestos de hecho de la norma de modo tal que se dé trato distinto a personas que, desde todos los puntos de vista legítimamente adoptables, se encuentran en la misma situación.

En otro plano, en el de la aplicación, la igualdad ante la Ley obliga a que ésta sea aplicada efectivamente de modo igual a todos aquéllos que se encuentran en la misma situación, sin que el aplicador pueda establecer diferencia alguna en razón de las personas o de circunstancias que no sean precisamente las presentes en la norma (Tribunal Constitucional, STC 144/1988, FJ 1).

Según el profesor Gálvez Muñoz, el principio de igualdad en este ámbito es definido por el Tribunal Constitucional, como la prohibición de toda diferencia de trato que carezca de una justificación objetiva y razonable, principio que considera vinculante tanto para el legislador como para los órganos que aplican el derecho. Con algunos matices también lo hace extensivo a los particulares, al estimar que su libertad de actuación sólo está limitada constitucionalmente por la prohibición de discriminar en los casos expresamente contemplados en el artículo 14. En los demás, debe estar de acuerdo con lo que establezcan las leyes y los jueces (Gálvez, 2003, p. 202). En consecuencia, el precepto mencionado, aunque no lo diga expresamente, engloba tanto la igualdad en la aplicación de la ley como la igualdad en el contenido de la ley (Díez-Picazo, 2005, p. 194).

\section{La igualdad en la aplicación de la ley}

Como se anotó inicialmente, la igualdad en la aplicación de la ley se identificaba en sus orígenes con el principio de legalidad. El órgano encargado de aplicar la norma no debía hacer distinciones diferentes a las que señalara el mismo precepto que debía aplicar. Este concepto de igualdad estaba ligado a un punto de vista formalista de la interpretación y aplicación del derecho, de tal suerte que la aplicación desigual de la ley se confundía con la violación de la propia ley (Fernández, 2002, pp. 62-63). De esta manera, se quebrantaba el principio de igualdad "no sólo si la ley por no ser norma general no contuviese una posible igualdad, sino también si al aplicar esa norma general no se hiciera de manera general, con abstracción de las personas concretas afectadas" (Rodríguez-Piñero \& Fernández, 1986, p. 21).

Esta sinonimia entre legalidad e igualdad se encuentra actualmente superada, pues ahora se aplican estos principios teniendo en cuenta el margen de apreciación o de discrecionalidad que permite la norma. Así, si el margen de apreciación es escaso, el principio de legalidad asume un papel preponderante, toda vez que la aplicación desigual de la ley se confunde con una inaplicación de la propia ley. En cambio, si el margen de apreciación es mayor, el principio de igualdad es el que debe jugar el papel más importante para evitar una arbitrariedad o injusticia en la aplicación de la ley (Rodríguez-Piñero \& Fernández, 1986, pp. 21-22). 
La igualdad en la aplicación de la ley, que era obligatoria para las autoridades administrativas, posteriormente se hizo extensiva a los órganos judiciales, lo cual impidió que éstos fallaran un caso de una manera y luego fallaran otro básicamente igual de forma distinta, salvo que justificaran debidamente el cambio de criterio.

De acuerdo con la jurisprudencia del Tribunal Constitucional, los requisitos para apreciar la vulneración del derecho a la igualdad en la aplicación de la ley en sede judicial, se relacionan, en primer lugar, con la acreditación de un término de comparación (tertium comparationis), habida cuenta que el juicio de igualdad sólo se puede realizar si se compara la resolución que se impugna y el precedente del mismo órgano judicial en un caso que sea básicamente igual. En segundo lugar, es condición que los supuestos que constituyen el término de comparación sean esencialmente iguales, pues únicamente en estos casos se puede pretender que la solución dada para uno sea igual a la del otro. Y en tercer lugar, es imperioso que las resoluciones objeto de la comparación procedan del mismo órgano judicial (Tribunal Constitucional, STC 133/2002, FJ 6).

Para el alto tribunal, un órgano judicial no puede fallar un caso de una manera y luego fallar otro sustancialmente igual de una manera distinta, a no ser que existan razones suficientes para que lo haga. Es válido que los órganos judiciales se aparten de sus propios precedentes judiciales, siempre y cuando expliquen sus motivos suficientemente 0 , a falta de una motivación expresa, que su proceder sea el resultado de un cambio de criterio:

[...] bien por inferirse con certeza del contenido de la propia resolución, bien por existir otros elementos de juicio externo que así lo indiquen, lo cual suele ocurrir cuando existen otros pronunciamientos posteriores coincidentes con la línea abierta por la resolución impugnada (Tribunal Constitucional, STC 74/2002, FJ 3).

\section{La igualdad en el contenido de la ley}

La igualdad formal no sólo está referida a la aplicación de la ley, sino también a la formulación del derecho. La generalidad de las normas y la justificación de las diferencias de trato son requisitos de la igualdad ante la ley. El primero de ellos está íntimamente ligado a la igualdad en la aplicación del derecho y parte del supuesto de que las normas son aplicables a más de una persona, esto es, que las leyes implantadas para un destinatario abstracto, no identificable ad personam, como suele ser el ciudadano general o un tipo genérico como el comprador, vendedor, funcionario, etc. Es por ello que la igualdad va a repercutir, en principio, sobre la estructura de las leyes, prohibiendo aquéllas que son personales (Fernández, 2002, pp. 68-70).

Sin embargo, es bueno señalar que el principio de igualdad no descarta la expedición de leyes ad personam. Éstas son permitidas siempre y cuando la individualización de sus destinatarios esté justificada, lo cual ha reconocido expresamente la jurisprudencia del Tribunal Constitucional al señalar:

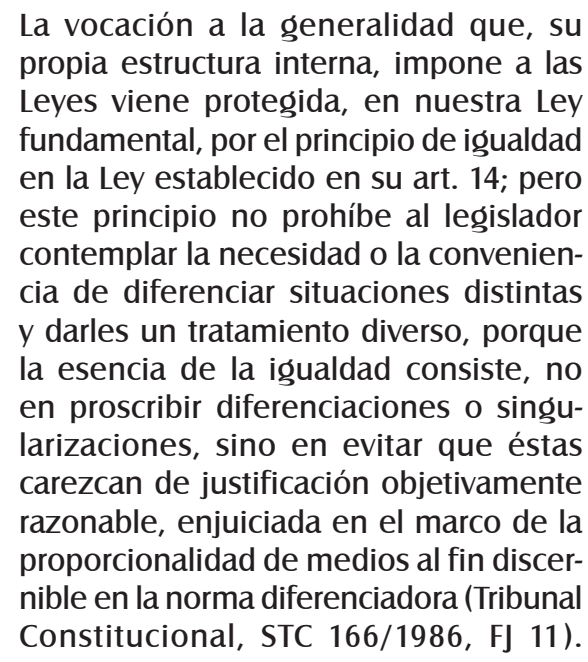

Ahora bien, con respecto a la expresión ley que se debe tener en cuenta como referencia para realizar el estudio del concepto de igualdad desde el punto de vista del contenido de la ley -lo cual implica que el legislador no dé un trato distinto 
a personas que se encuentren en la misma situación-, se debe anotar que la misma doctrina y jurisprudencia han aclarado que en el artículo 14 de la Constitución española, el término "ley" se utiliza como sinónimo de norma jurídica, en consecuencia, se debe entender en sentido amplio, englobando leyes, reglamentos (Rodríguez-Piñero \& Fernández, 1986, p. 40) y cualquier otra norma jurídica del ordenamiento jurídico español, como los convenios colectivos ${ }^{15}$, siendo el mandato de igualdad en el contenido de la ley, consagrado en la norma mencionada, una prohibición de cualquier tipo de discriminación normativa (DíezPicazo, 2005, pp. 197-198).

Igualmente, es pertinente anotar que el problema de la igualdad de trato debe ser planteado con respecto a los derechos o a los deberes concretos, para que operen como términos de comparación (tertium comparationis).

En cuanto a los criterios que se deben emplear para apreciar la igualdad de trato, se señalan el de la igualdad numérica y el de la igualdad proporcional. El primero, se condensa en la fórmula "lo mismo a todos" y exige dar idénticos beneficios o cargas a todos los miembros del grupo. El segundo criterio, corresponde al enunciado "lo mismo a los iguales", lo cual significa que el trato debe ser parejo para quienes se encuentren en situación similar y desigual entre quienes se encuentren en situaciones distintas (Díez-Picazo, 2005, pp. 199-200).

Para que haya una vulneración del principio de igualdad, desde el prisma del contenido de la ley, no basta que una norma establezca una desigualdad, sino que ésta sea irrazonable, es decir, no esté

15 De acuerdo con el Tribunal Constitucional, el convenio colectivo, en suma, en cuanto tiene valor normativo y se inscribe en el sistema de fuentes, ha de someterse a las normas de mayor rango jerárquico y ha de respetar el cuadro de derechos fundamentales acogidos en nuestra Constitución y, en concreto, las exigencias indeclinables del derecho a la igualdad y a la no discriminación, sin que ello suponga que toda distinción dentro del convenio colectivo sea per se contraria al principio de igualdad (STC 27/2004, FJ 4). justificada, pues no toda desigualdad constituye una discriminación. Los parámetros utilizados para determinar si la desigualdad de trato está o no justificada, es de una parte la finalidad perseguida por la norma y de otra, que la norma diferenciadora tenga una estructura coherente, por lo tanto, existe una adecuación suficiente entre la finalidad de la norma y los medios empleados, esto es, la diferencia de trato (Fernández, 2002, pp. 74-75).

Para finalizar este punto, se debe anotar que según el Tribunal Constitucional, de la igualdad contenida en el artículo 14 de la Constitución se desprende un derecho subjetivo a favor del ciudadano y una obligación para los poderes públicos, lo cual explicó en su sentencia STC No. 2/83 en la que dice:

El principio de igualdad ante la Ley consagrado en el art. 14 de la C.E., ha sido configurado, en la parte que aquí interesa, por la doctrina reiterada de este Tribunal, y de la que son especiales exponentes las Sentencias de 14 y 22 de julio de 1982, como un derecho subjetivo de los ciudadanos a obtener un trato igual, que obliga y limita a los poderes públicos a respetarlo, y que exige que los supuestos de hecho iguales sean tratados idénticamente en sus consecuencias jurídicas, abarcando también a la igualdad en la aplicación de la Ley, de manera que un mismo órgano jurisdiccional no pueda, en casos sustancialmente iguales, modificar arbitrariamente el sentido de sus resoluciones, salvo cuando su apartamiento de los precedentes posea una fundamentación suficiente y razonada, y que en los supuestos de decisiones desiguales, debidas a órganos plurales, corresponde a la jurisprudencia de los órganos jurisdiccionales de superior rango, establecer la necesaria uniformidad en la aplicación de la Ley, en pro de la seguridad jurídica.

\section{La igualdad material}

En el Estado social y democrático de derecho, el concepto de igualdad material exige que los poderes públicos tomen medidas para alcanzar un reequilibrio de las desigualdades existentes en la 
sociedad. Por ello, el artículo 9.2 de la Constitución contiene una finalidad que deben cumplir los poderes públicos, con miras a que éstos tomen las medidas necesarias para tratar de lograr la igualdad efectiva. Se trata de asegurar un mínimo vital indispensable para asegurar el respeto a la dignidad de la persona y el ejercicio de los derechos fundamentales (Carmona, 1994, p. 283). El Tribunal Constitucional explica que:

\section{[...] el artículo 9.2 CE expresa la voluntad del constituyente de alcanzar no sólo la igualdad formal sino también la igualdad sustantiva, al ser consciente de que úni- camente desde esa igualdad sustantiva es posible la realización efectiva del libre desarrollo de la personalidad; por ello el constituyente completa la vertiente negativa de proscripción de acciones discriminatorias con la positiva de favo- recimiento de esa igualdad material (Tri- bunal Constitucional, STC 12/2008, FJ 4).}

Si se tiene en cuenta que en todas las sociedades políticamente organizadas se presentan desigualdades sociales y económicas entre los miembros de la comunidad, una interpretación material y sistemática del principio de igualdad entraña la exigencia de que sea el Estado el encargado de hacer realidad este principio. No es suficiente que el Estado se abstenga de dictar normas discriminatorias sin justificación razonable, sino que ha de tomar medidas para conseguir la igualdad efectiva de todos los ciudadanos (Carmona, 1994, p. 271-272).

Cabe señalar que si bien el artículo 9.2 no es objeto de recurso de amparo, a diferencia de la igualdad formal contenida en el artículo 14 de la Constitución, sí irradia, por ser parte del título preliminar de la Constitución, al propio artículo 14 como al resto del ordenamiento jurídico, lo que implica que la igualdad formal (artículo 14) se deba interpretar a la luz de la igualdad sustancial (Suárez, 1997, p. 265).

\section{La igualdad como derecho}

Este es un tema que, tanto a nivel jurisprudencial como doctrinal, no ha sido pacífico. Algunos consideran que la igualdad no es un derecho, otros, aunque no lo niegan, no lo consideran un derecho fundamental con sustantividad propia y hay otros que sí la consideran un verdadero derecho con contenido propio: el derecho a un trato igualitario.

\section{La igualdad no entendida como derecho}

Para el profesor Pérez Royo, la igualdad constitucional no es ni puede ser un derecho. El derecho a la igualdad, de existir, significaría la negación de la individualidad del ser humano y, por lo tanto, la negación de todos los demás derechos. Si los individuos gozaran del derecho a ser iguales, el ejercicio de los demás derechos sería imposible, por cuanto cada vez que se ejerce de manera individual un derecho, se está diferenciando de los otros. Más con respecto a unos y menos con respecto a otros, pero siempre con respecto a todos (2003, pp. 293-294).

El derecho se inventó para hacer valer la diferencia individual, es decir, no para que todos seamos iguales, sino para que cada uno tenga derecho a ser diferente. Por ello, la igualdad no es más que una técnica para la gestión de las diferencias personales. La convivencia humana no ha sido nunca una coexistencia animal, pues ha descansado siempre en ficciones, en entes de razón inventados para hacer prevalecer la política sobre la animalidad en sus relaciones. En la definición de las diversas formas de expresión de la convivencia humana han desempeñado un papel importante, tanto la igualdad como la desigualdad, por ser las ficciones que la han explicado y justificado (Pérez, 2003, pp. 294-297). Pérez Royo agrega que si bien ambas categorías son ficciones, no lo son de la misma manera.

La desigualdad es la ficción menos correctora de nuestra condición animal. Es una forma poco modificada de la ley del más fuerte, que goza de credibilidad, la cual, en cuanto principio definidor y justificador de la convivencia humana, ha sido 
considerado como algo evidente. Igualmente, tiene la ventaja de constituir un principio de orden, pues una sociedad organizada con base en esta categoría es naturalmente ordenada, así nos parezca una sociedad injustamente conformada. La jerarquización, consecuencia de la formalización política de las diferencias personales, es uno de los métodos más estables de convivencia hasta ahora conocidos (Pérez, 2003, pp. 298-299).

Una cuestión diferente sucede con la igualdad. La igualdad es exclusivamente artificial y se encuentra aparentemente en contradicción con la realidad, por la forma como es percibida por los individuos. El esfuerzo mental para pasar de las diferencias personales a la igualdad, es notable. Casi nadie estima que los seres humanos son iguales y, sin embargo, se considera a la igualdad como la categoría que preside la organización de la convivencia. La igualdad, como ficción creíble y principio de orden, es una construcción de tipo constitucional, que es el resultado de la concurrencia de dos principios: un principio antropológico universal, pero particular (de carácter sustantivo) y de un principio político territorialmente limitado, pero general (de carácter general) (Pérez, 2003, pp. 299-300).

El principio antropológico se identifica con la dignidad de los seres humanos. Éstos son iguales en la medida en que son titulares de una dignidad común, la dignidad humana, característica que, por demás, distingue a los seres humanos de los otros individuos del reino animal. Este elemento constitutivo de la igualdad es complejo de definir debido a su naturaleza universal y jurídica que impiden alcanzar un acuerdo total sobre el punto, por lo tanto, el contenido del concepto de dignidad humana se reconduce a un contenido mínimo, es decir, a aquél aspecto que nadie pone en discusión: la voluntad humana. En ésta reside tanto el fundamento de la diferencia como de la igualdad, pues, por una parte, permite a cada uno de nosotros conducirnos de acuerdo con nuestro libre albedrío, y por otra, por ser todos titulares de ella, nos hace iguales. Por ello la dignidad humana que, en principio es un concepto universal, es un elemento necesario para la comprensión del derecho, ya que sin voluntad no hay derecho, sino dominación personal (Pérez, 2003, pp. 300-301).

Ahora bien, este principio antropológico, por gozar también de un carácter particular (predicarse de cada ser humano), no es suficiente para explicar y justificar la existencia de una sociedad igualitaria; de ahí la necesidad de otros elementos: el político y la voluntad general. Con respecto a este último, la voluntad general no aprecia la voluntad de los individuos en cuanto tales sino como ciudadanos. El recurso para llegar a ella es el derecho al sufragio, que cuando se ejercita es el único momento en el cual el ser humano es exactamente igual a otro. Esta homogeneidad de voluntades heterogéneas, exclusivamente política, es la formadora de la voluntad general y el segundo componente de la igualdad constitucional en la que se traduce la democracia. En ese instante de la formación de la voluntad general descansa el derecho a la diferencia. Sin la existencia de la igualdad, en la conformación de aquélla, existiría la diferencia, pero no el derecho a ella (Pérez, 2003, pp. 301-306).

El autor concluye, que por ser la voluntad general la regla de la igualdad, no es jurídica, sino política. El punto de conexión entre la igualdad política y el derecho es la igualdad constitucional, si se tiene en cuenta que la Constitución es el punto de llegada de la política y el punto de partida del derecho. Con base en lo anterior, se puede decir que la igualdad sólo existe "como presupuesto político para que las relaciones sociales puedan ser relaciones jurídicas. La igualdad constitucional no es un derecho fundamental, sino el presupuesto de todos los derechos fundamentales" (Pérez, 2003, p. 307).

La profesora Zoco Zabala, analiza el tema desde el prisma estricto del derecho positivo y llega a la conclusión de que la igualdad no es un derecho subjetivo a un trato igual en general, pues la fa- 
cultad de disposición predicable de este tipo de derechos adquiere significación siempre y cuando se concrete su objeto en una norma stricto sensu dada al caso. De ahí que la igualdad ante la ley constituirá un derecho subjetivo sólo cuando se establezca en un precepto jurídico que determine su alcance.

Por faltar el objeto determinado que se despliega en el ejercicio del derecho subjetivo, la igualdad ante la ley no constituye un derecho, sino la aplicación de un principio, pues es preciso delimitar frente a quién y respecto a qué norma se tiene, en estricto sentido, derecho a un trato igual (Zoco, 2003, pp. 50-51).

Para ella, la ubicación del artículo 14 en el preámbulo de la Sección 1a. de la Constitución, bajo el enunciado "De los Derechos Fundamentales y de las Libertades Públicas", contrario a lo planteado por un sector de la doctrina, constituye un argumento más para reafirmar su naturaleza de principio. Es el lugar donde se encuentra ubicado aquel precepto, el argumento para reforzar su naturaleza de principio del que derivan otras tantas titularidades subjetivas, sea de las descritas en las normas de la Sección 1a, Capítulo II, Título I, o de las reguladas en la ley que sirvan para ello. Igualmente, se debe tener en cuenta, que el contenido esencial del artículo 14, irradia el ordenamiento jurídico, pues la igualdad ante la ley está presente en cualquier norma reguladora de derechos (Zoco, 2003, pp. 52-53).

El artículo 14 no es una norma que reconozca un derecho, como se podría inferir del sentido literal del artículo 53.2 CE, sino un principio del cual se podrían derivar titularidades subjetivas.

Este carácter esencial del artículo $14 \mathrm{CE}$ determina la posibilidad de interponer recurso de amparo 'ante los tribunales ordinarios por un procedimiento basado en los principios de preferencia y sumariedad y, en su caso, a través del recurso de amparo ante el Tribunal Constitucional' (art. 53.2 CE) (Zoco, 2003, p. 53).
En suma, la autora mencionada, en su estudio "sobre la igualdad en la aplicación de las normas y motivación de sentencias", concluye -prácticamente como lo hace el profesor Pérez Royo-que la igualdad contenida en el artículo 14 CE no es un derecho, sino un principio estructurador de todos los derechos ${ }^{16}$, exigencia que debe vincular al juez $y$ al legislador. Al juez, en cuanto tiene el deber de proyectar las normas generales y abstractas a supuestos de hecho concretos, de modo que el paso de lo general a lo particular se haga mediante un pronunciamiento motivado. Asimismo, el legislador deberá respetar dicho principio, habida cuenta de que las diferencias determinadas en la ley deben ser razonables y encontrarse justificadas (Zoco, 2003, p. 57).

Cabe señalar que la profesora Zoco Zabala no hace una distinción significativa entre la igualdad como valor contenido en el artículo 1.1 CE y la igualdad como principio contenido en el artículo 14 CE. Por el contrario, es de la opinión que los valores y los principios se identifican porque gozan de eficacia jurídica. La igualdad, como valor del ordenamiento jurídico, se incorpora en el principio de igualdad ante la ley, por lo que se constituye desde este prisma en el soporte de la interpretación del ordenamiento jurídico, el faro que va orientar la evolución de la norma constitucional, y el parámetro para delimitar la legitimidad de las diversas manifestaciones del sistema de legalidad.

La igualdad que protege el artículo 1.1 CE tiene el mismo significado que la del artículo $14 \mathrm{CE}$, aunque la eficacia jurídica de este ultimo sea mayor. El mandato de igualdad en el ordenamiento jurídico español, desplegado por el artículos 1.1 CE se proyecta singularmente sobre el artículo $14 \mathrm{CE}$, de ahí que ambos expresen un mismo contenido:

16 De similar posición es el profesor Martínez García, quien considera que "la igualdad no es aquí un derecho Fundamental más, sino un elemento estructural de todo el derecho" (citado por Puy, 1991, p. 140). 
la igualdad del ordenamiento jurídico (Zoco, 2003, pp. 34-37).

Por su parte, el profesor Ignacio De Otto también considera que la igualdad contenida en el artículo 14 CE no es un derecho subjetivo, pues si bien el artículo 53.2 CE protege el principio de igualdad por medio del recurso de amparo que pueden interponer quienes estimen que se ha violado su derecho; sin embargo, de esto no se podría afirmar que se trata de un precepto que reconoce un derecho subjetivo de todos a ser tratados por igual, un derecho subjetivo de la misma naturaleza que los demás reconocidos en la Constitución.

No es posible elevar la igualdad a derecho subjetivo, por cuanto el artículo $14 \mathrm{CE}$, en sí mismo, no es suficiente para determinar el aspecto esencial de un derecho subjetivo en sentido propio: un objeto. El derecho a un trato igual requiere previamente que haya una materia u objeto tratados por otras normas que establezcan relaciones jurídicas. No existe un derecho subjetivo a la igualdad por la misma razón que no hay un derecho a la equidad, el cual es principio configurador, pero no constitutivo de relaciones jurídicas (De Otto, 1984, p. 450).

En el fondo, el fin perseguido por el principio de igualdad tiene como principal efecto ampliar las materias susceptibles de recurso de amparo $y$, por lo tanto, la viabilidad que los ciudadanos demanden un examen jurisdiccional de la constitucionalidad de las normas y de los actos cuando también afectan derechos que no tienen el carácter de fundamentales.

La posibilidad de que en éste se invoque el principio de igualdad permite llevar ante el Tribunal Constitucional pretensiones relativas a cualquier norma-pensiones, igualdad de los hijos, edad de jubilación, etc., aunque está en sí misma considerada no afecte a derechos susceptibles de amparo (De Otto, 1984, pp. 450-451).

\section{La igualdad entendida como un derecho subjetivo no autónomo}

En esta línea se encuentran aquellos doctrinantes, que, a pesar de reconocer la igualdad como un verdadero derecho subjetivo, no le reconocen autonomía propia, por cuanto su contenido siempre viene establecido con respecto a las relaciones jurídicas concretas. Con base en esto, el profesor José Suay estima que la Constitución española establece claramente el juicio de igualdad como un derecho subjetivo, puesto que si no lo fuera, no se podría interponer, por violación del derecho a la igualdad, un recurso de amparo, el cual, no se debe olvidar, tiene como finalidad servir de garantía frente a los derechos fundamentales. Con todo, considera que esta situación no implica que la igualdad haya dejado de ser un principio inspirador del ordenamiento jurídico, es decir, orientador de la actividad de los poderes públicos. El reconocimiento que el artículo 14 CE establece un derecho subjetivo a obtener un trato igual, se encuentra acorde o en sintonía con la última doctrina expuesta a partir de la obra de Leibholz, la cual, si bien ha suscitado controversia, es la que mejor se ajusta al artículo 53.2 (Suay, 1985, p. 149).

Para reforzar su posición, Suay argumenta que la igualdad es un derecho que participa de las características propias de los demás derechos fundamentales, tales como su vinculatoriedad inmediata, es decir, que no requiere desarrollo legal para ser invocada, toda vez que el artículo 53.1 CE declara que los derechos y libertades públicas reconocidas en dicho capítulo (II) vinculan a todos los poderes públicos; el artículo 14 CE queda incluido dentro de éste.

En cuanto a si este reconocimiento de la igualdad como derecho subjetivo le era aplicable, al analizar la cuestión de si el contenido del derecho a la igualdad de trato es en parte esencial, y en parte no esencial con miras a establecer si lo que preceptúa el segundo inciso del art. 53.1 CE, Suay 
llega a la conclusión que sí se puede aplicar a la igualdad de trato, por cuanto no tiene un carácter autónomo, sino que es un derecho que no tiene una vida propia y siempre aparece en relación con otro (Suay, 1985, p. 149-152).

Además de ese carácter no autónomo del derecho a la igualdad, se resalta su carácter formal, pues -según Suay-, a pesar de que el Tribunal Constitucional no lo haya expresado categóricamente, por la forma como se encuentra redactado el artículo $14 \mathrm{CE}$, no cabe otra posibilidad. De esta manera, por la sola invocación de esta norma los "tribunales no pueden colocar a quien se encuentra en un situación de hecho desventajosa respecto de otra en la misma situación que éste ocupa" (Suay, 1985, p. 152), por cuanto no se está en presencia de un derecho material, sino formal. La norma es la que se utiliza como medida para establecer si se violó o no el artículo 14 y lo puede infringir quien tiene una situación de hecho favorable, como quien padece otra desfavorable.

Otro doctrinante, que transita por este sendero es el profesor Gálvez Muñoz, quien estima que la cláusula general de igualdad, en su doble condición de igualdad ante la ley y de proscripción de toda discriminación, se encuentra recogida en el artículo 14 de la Constitución, el cual actúa como pórtico del Capítulo II del Título I, siendo ésta la parte de la Constitución dedicada a la declaración de los derechos y las libertades más relevantes, es decir, aquéllos que merecen, en sentido amplio, el nombre de fundamentales. Por lo tanto, constituye la antesala tanto de la sección primera de ese Capítulo -artículos15 a 29, que son los que cuentan con un grado de protección jurisdiccional reforzada-, como de la sección segunda -artículos 30 a 38 que tienen un nivel de protección jurisdiccional que se podría denominar ordinario. Esta ubicación del precepto expresa su compleja naturaleza de derecho genérico y, por lo tanto, su carácter esencialmente relacional. A pesar de ser un derecho que goza de entidad propia, siempre se presenta acompañado de otro; por esta razón es un derecho y un principio general a la vez (Gálvez, 2003, p. 195).

Su carácter relacional y no autónomo no permite que el artículo 14 sea objeto de desarrollo legislativo del artículo 14. En efecto, el hecho de que la igualdad no se pueda predicar en abstracto, sino únicamente con respecto a las relaciones jurídicas concretas, impide que este principio pueda ser objeto de una regulación o desarrollo normativo con carácter general. Las normas individuales dictadas en los distintos campos o áreas son las que tienen que plasmar el principio de igualdad (Gálvez, 2003, p. 197).

En este mismo sentido se ha expresado la jurisprudencia del Tribunal Constitucional, al señalar que:

[...] existe, pues, una exclusión expresa del art. 14 en el art. 81.1 de la Constitución. Tal exclusión, por otra parte, está justificada porque la igualdad reconocida en el art. 14 no constituye un derecho subjetivo autónomo, existente por sí mismo, pues su contenido viene establecido siempre respecto de relaciones jurídicas concretas. De aquí que pueda ser objeto de amparo en la medida en que se cuestione si tal derecho ha sido vulnerado en una concreta relación jurídica $y$, en cambio, no pueda ser objeto de una regulación o desarrollo normativo con carácter general (Tribunal Constitucional, STC 76/1983, FJ 3).

Por su parte, el profesor Baño León considera que si bien la igualdad por sí misma no existe, ello no le quita la particularidad de ser un derecho subjetivo, como quiera "que el objeto de la igualdad no se identifica con el objeto del derecho" (Baño, 1987, p. 182), pues de no existir el derecho a la igualdad, la víctima de la discriminación con respecto al disfrute de un derecho o relación jurídica no podría exigir la reparación (Baño, 1987). Con respecto al hecho del contenido relacional del objeto de la igualdad (equiparación), opina que esta situación no enerva su carácter subjetivo, si 
se tiene en cuenta que el contenido de la igualdad está constituido por el conjunto de facultades que al titular del derecho se le ofrece para conseguir el restablecimiento de éste (Baño, 1987, p. 183).

También argumenta que la Constitución española ha establecido la igualdad como un verdadero derecho público subjetivo, así como la vía procesal para hacerlo efectivo (53.2 CE). Asimismo, piensa que por encima del acierto o desacierto de consagrarla como un derecho subjetivo, la Constitución se decidió ideológicamente en el sentido apuntado por Zagrebelsky, el cual se refiere a que sólo cuando la igualdad se concibe como derecho subjetivo se tiene la posibilidad de situarla entre los derechos inviolables del hombre (Baño, 1987, p. 184).

\section{Baño León sentencia que:}

[...] la igualdad, como derecho subjetivo fundamental, encierra como contenido de una situación jurídica de poder y otra de deber. El derecho a la igualdad obliga al Estado a abstenerse de utilizar o emplear criterios discriminatorios. El derecho a la igualdad faculta al individuo para exigir la equiparación en el trato, cuando considera que el Estado ha incumplido su deber publico de no actuar discriminatoriamente (Baño, 1987, p. 188).

\section{La igualdad entendida como un derecho} autónomo

Hay otro sector de la doctrina que reconoce la igualdad como un derecho con vida propia. El profesor Puy, al responder el cuestionamiento de que la igualdad no es un derecho fundamental porque se demanda conectado generalmente a otros derechos, que son los denominados fundamentales, estima que una cosa no imposibilita la otra. Así, por ejemplo, la libertad y la justicia son valores y principios adjetivos con respecto a otros, sin perjuicio de serlo ellos mismos, de modo autónomo o desligados de los demás (Puy, 1991, p. 152).

De igual forma, estima, desde un fundamento iusnaturalista, que el derecho a la igualdad debe ser considerado un derecho fundamental, porque existe una inclinación natural a la igualdad, como se puede observar en el análisis de la naturaleza humana que manifiesta que en ella existe una tendencia inevitable hacia la autopersonalización, la cual se funda "en la necesidad de asimilarse al modelo medio de los demás individuos componentes del grupo de referencia en que se instala cada uno" (Puy, 1991, p. 148). Los individuos componentes del grupo siempre están en una permanente búsqueda de una participación equivalente con respecto al conjunto de bienes, virtudes y valores que comparten, coaprecian y coejercitan todos los demás, por ello el derecho a la igualdad es el reconocimiento que todos tienen de poder satisfacer esa necesidad, so pena de que los que no lo logren puedan convertirse en perturbadores del bienestar de todos y de cada uno.

Desde esta perspectiva, la igualdad debe ser regulada, juzgada y calificada como un verdadero derecho fundamental, pues su razón de ser se encuentra en la satisfacción de una necesidad vital de la naturaleza humana (Puy, 1991, p. 153). Puy también hace notar que la naturaleza humana permite justificar el contenido normativo del derecho, motivo por el cual el derecho a la igualdad se manifiesta de dos formas: por un lado, como derecho a no ser discriminado (igualdad de no discriminación) y, por otro, como derecho a ser protegido y ayudado en similares condiciones a las prestadas a los demás miembros del grupo de referencia (igualdad de oportunidades).

El primero de los aspectos, conlleva, a su vez, el derecho a ser calificado indistintamente por las normas, así como el derecho a ser tratado imparcialmente por todos los administradores. Estos aspectos se reflejan al definir el derecho a la igualdad, como:

[...] el derecho fundamental que tiene todo ser humano, frente a todos los poderes públicos, estatales o sociales; y para toda la gestión pública, pero en especial 
la normativa, $1^{\circ}$ ) a ser calificado indiscriminadamente por la ley, $2^{\circ}$ ) a ser tratados imparcialmente por los administradores, y $\left.3^{\circ}\right)$ a recibir de todos los operadores sociales, dentro del grupo de referencia, un número de oportunidades de ejercicio de todos los derechos y libertades, equivalente al que reciban los más afortunados consocios (Puy, 1991, pp. 149-150).

Desde el prisma de la definición también es evidente que la igualdad es un derecho fundamental, pues los argumentos esgrimidos para negar esta característica no son concluyentes.

Algunos argumentan que la igualdad no debe ser un derecho fundamental, porque no se puede establecer el derecho a la igualdad de cada uno con la igualdad de derechos para todos, es decir, porque no se puede distinguir la igualdad-valor, la igualdad-principio y la igualdad-derecho. Este cuestionamiento lo rebate Puy, argumentando que la igualdad es una y la misma en los tres eventos señalados, lo único que los diferencia es el discurso desde el que se plantean.

\begin{abstract}
La misma igualdad es igualdad-valor en el discurso ético-político; es igualdad-principio en el discurso jurídico-normativo; y es igualdad-derecho en el discurso jurídicopostulativo. El discurso constitucional es, naturalmente, un discurso jurídiconormativo que trata sustancialmente de la igualdad-principio (o igualdad regla o igualdad norma) pero por eso mismo da por antecedente la igualdad valor $y$ legitima como consecuente la igualdadderecho. Sin estas dos nociones de la igualdad-valor y de la igualdad-derechofundamental, carecería de sentido y función el supuesto eje principal de la igualdad principio (Puy, 1991, p. 153).
\end{abstract}

Con respecto al otro cuestionamiento que también niega la característica de derecho fundamental a la igualdad, porque el principio de igualdad tiene un mandato indeterminable, tampoco lo comparte, porque -en su entender- aquél tiene formulas perfectamente definidas, como "obra de tal manera que tu trato tienda a nivelar a los inferiores por el ras de los superiores" o "trata a todos de la misma manera" o "no discriminarás" y en otra, que se encuentra en la doctrina legal y profesoral contemporánea (Puy, 1991).

Otros doctrinantes que ven en la igualdad un derecho autónomo son Miguel Rodríguez Piñero y María Fernanda Fernández, quienes consideran la ubicación de la igualdad y de la discriminación en forma separada del resto de los derechos enunciados en el Título II; contrario a lo que muchos pueden pensar, es un indicio de su trascendencia como traducción de la voluntad del legislador de elevar la igualdad al rango de puntal fundamental del orden social, pues no parece que sea otra la doctrina del Tribunal Constitucional, cuando afirma que "el artículo 14 de la Constitución, al establecer el principio general de que los españoles son iguales ante la ley, establece un derecho subjetivo a obtener un trato igual" (Tribunal Constitucional, STC 49/1982), derecho subjetivo, que en sí es un derecho fundamental autónomo (RodríguezPiñero \& Fernández, 1986, pp. 252-253).

Al ciudadano le asiste un derecho a ser tratado de forma igual; este derecho es objeto de protección en los mismos términos de los demás derechos fundamentales, no por asimilación al régimen jurídico de éstos, sino con plena identificación en cuanto a su naturaleza (Rodríguez-Piñero \& Fernández, 1986, p. 255).

El tratadista Pérez Luño también participa de esta corriente, argumentando que la condición de derecho fundamental de la igualdad formal sancionada en el artículo 14 CE se comprueba por su inclusión en el Capítulo Segundo del Título I de la Constitución, así como por su garantía reforzada dispuesta, entre otros casos, en el artículo 53.2 de la CE para la tutela de la violación de este derecho. Igualmente, estima que de objetarse su carácter de derecho fundamental autónomo por el hecho de no aparecer incluido en la Sección 1a. (De los Derechos Fundamentales y de las Libertades Públicas) del 
Capítulo Segundo del Título I de la Constitución, se negaría la misma condición a muchos otros derechos y libertades reconocidos en el texto constitucional. La igualdad, como derecho fundamental, tiende a asegurar un delimitado estatus, "es decir, una determinada esfera de intereses de los ciudadanos, aquí concretado en la garantía de paridad de trato y la consiguiente prohibición de una serie -no cerrada, ni exhaustiva- de discriminaciones" (Pérez, 1987, 151).

\section{CONCLUSIONES}

Si bien el concepto de igualdad estuvo presente en el ideal de las sociedades políticas que antecedieron al Estado de derecho, sólo con el surgimiento de éste se erigió como un valor guía de la actividad de los poderes públicos.

La positivización de la igualdad ante la ley se identificó con la generalidad de la ley, idea que más tarde evolucionó, por obra del derecho administrativo, en el sentido en que ya no bastaba que la ley fuera general e impersonal, sino que debía tener un alcance mayor en el sentido de exigir que fuera aplicada sin excepciones ni consideraciones personales (igualdad en la aplicación de la ley).

Con el advenimiento de los Estados Constitucionales se va a permitir controlar el contenido de la ley (igualdad en la ley), control que en Europa se introduce al mismo tiempo que el control de constitucionalidad. De esta forma, la igualdad ante la ley engloba tanto la igualdad en la aplicación de la ley como la igualdad en su contenido.

Al lado de la igualdad formal, se reconoce una igualdad material, la cual se ubica históricamente en Europa a partir de la Constitución de Weimar, lo que significa la conexión entre la realidad social y el ordenamiento jurídico. Estos conceptos se van a plasmar en la Constitución Española en su forma más evolucionada, es decir, como un valor, un derecho y un principio en sus dos vertientes: igualdad formal y material.
Como valor se consagra la igualdad en el art. 1.1 CE, por lo tanto, se convierte en uno de los objetivos que el sistema jurídico político español se propone alcanzar, sujetando a los poderes públicos de forma negativa, es decir, que las normas y los actos contrarios a este ideal son inconstitucionales, $y$ de una manera positiva, mandándoles actuar de tal forma que impulsen la igualdad real o material, con el objeto de asegurar la igualdad de oportunidades en la comunidad. En consecuencia, la igualdad adquiere una dimensión fundamentadora, orientadora y crítica. La igualdad, como principio, se encuentra consagrada en su doble dimensión en los artículos 14 CE (igualdad formal) y 9 CE (igualdad material).

En cuanto a la primera dimensión (igualdad formal), así no lo señale expresamente la Constitución, se ha entendido por parte de la doctrina y de la jurisprudencia que aquélla contiene el respeto por "la igualdad en la ley" y "la igualdad en la aplicación de la ley"; de esta manera, se acopla a toda la tradición constitucional europea y norteamericana al amparar no sólo el "acto justo" -igual tratamiento a todos los que se hallan sometidos a una misma disposición jurídica-, sino también “la regla justa", ausencia de distinciones injustificadas en el contenido legal. Como bien lo anotó la jurisprudencia constitucional, este principio origina un derecho subjetivo a favor del ciudadano a obtener un trato igual y una obligación para los poderes públicos a respetarlo.

Con respeto a la segunda dimensión (igualdad material), ésta exige, por ser España un Estado social de derecho, que las medidas tomadas por lo poderes públicos giren en torno a lograr el reequilibrio de las desigualdades existentes dentro de la sociedad. Se trata de asegurar un mínimo vital indispensable para asegurar el respeto a la dignidad de la persona y el ejercicio de los derechos fundamentales, o en palabras del Tribunal Constitucional, con este principio se procura alcanzar no sólo la igualdad formal, sino también la igualdad sustantiva, de ahí que el constituyente haya 
completado la vertiente negativa de proscripción de acciones discriminatorias con la positiva de favorecimiento de esa igualdad material.

La igualdad como derecho se encuentra igualmente consagrada en el artículo 14, aunque esta apreciación no ha sido de recibo pacífico, pues algunos consideran que no lo es, ya sea porque lo consideran un principio o porque, según algunos, de existir el derecho a la igualdad significaría la negación de la individualidad del ser humano y, por lo tanto, la negación de todos los demás derechos.

La igualdad, como derecho, sea porque se considere un derecho autónomo o no, se comprueba, como lo anota la doctrina, por su inclusión en el Capítulo Segundo del Título I de la Constitución, así como por su garantía reforzada dispuesta, entre otros casos, en el artículo 53.2 de la CE para la tutela de la violación de este derecho.

Ahora bien, respondiendo a la inquietud que me llevó a realizar este trabajo, dada la literatura que negaba la igualdad como derecho, debo señalar que la igualdad es un valor, un principio y un verdadero derecho, pues no se puede excluir ninguno de estos términos, no sólo porque desde el prisma de un sector de la doctrina y del derecho positivo (Constitución española) permite llegar a esta conclusión, sino también porque, como bien lo anota el profesor Francisco Puy, la "igualdad es una y la misma en los tres eventos señalados, lo único diferente es el discurso desde donde se plantee".

\section{REFERENCIAS}

Baño L., J.M. (1987). La igualdad como derecho subjetivo. Revista de Administración Pública, 114.

Berlin, I. (1983). Conceptos y categorías. México: Fondo de Cultura Económica.

Carmona C., E. (1994). El principio de igualdad material en la jurisprudencia del Tribunal Constitucional. Revista de Estudios Políticos, 84.
De Otto, I. (1984). Igualdad. En Diccionario del Sistema Político Español. Madrid: Akal.

Díaz R., F.J. (1997). Valores superiores e interpretación constitucional. Madrid: Centro de Estudios Políticos y Constitucionales.

Díez-Picazo, L.M. (2005). Sistema de derechos fundamentales. Navarra: Editorial Aranzadi.

Fernández, E. (2002). Igualdad y Derechos Humanos. Madrid: Tecnos.

Gálvez, J. (1985). Comentarios a la Constitución Española. Madrid: Civitas.

Gálvez M., L. (2003). La cláusula general de igualdad. Revista Anales de Derecho, 21.

Giménez G., D. (1999) Una manifestación polémica del principio de igualdad: acciones positivas moderadas y medidas de discriminación inversa. Valencia: Tirant Lo Blanch.

Hart, Herbert L.A. (1998). El concepto de derecho (Genaro Carrió, traductor). Buenos Aires: AbeledoPerrot.

Martín C., J. (1998). El concepto de "igualdad" en una democracia avanzada: un estudio de la jurisprudencia del Tribunal Constitucional. Revista española de Derecho Constitucional, año 18 (53).

Martín V., M.Á. (2003). Evolución del principio de igualdad en Estados Unidos- nacimiento y desarrollo de las medidas de acción afirmativa en Derecho estadoudinense. Revista española de Derecho Constitucional, año 23 (68).

Ollero T., A. (1989). Igualdad en la aplicación de la ley y precedente judicial. Madrid: Centro de Estudios Constitucionales.

Peces-Barba M., G. (1999). Curso de Derechos Fundamentales. Madrid: Universidad Carlos III de Madrid. 
Pérez L., A.E. (1987). Sobre la igualdad en la Constitución Española. Anuario de Filosofía del Derecho, 4.

Pérez R., J. (2003). Curso de Derecho Constitucional. Madrid: Marcial Pons.

Puy M., F.P. (1991). El derecho a la igualdad en la Constitución Española. En El principio de igualdad en la Constitución Española: XI Jornadas de Estudio (Vol. I). Madrid: Ministerio de Justicia.

Puyol, Á. (2001). El discurso de la igualdad. Barcelona: Crítica.

Rey M., F. (1995). El derecho fundamental a no ser discriminado por razón del sexo. Madrid: Mc Graw Hil.

Rodríguez-Piñero, M. \& Fernández L., M.F. (1986). Igualdad y discriminación. Madrid: Tecnos.
Rubio L., F. (1991). La igualdad en la jurisprudencia del Tribunal Constitucional. Revista española de Derecho Constitucional, 31.

Suárez P., G. \& Américo C., F. (1997). Artículo 14Igualdad ante la Ley. En Comentarios a la Constitución Española de 1978 (Tomo II). Madrid: Cortes Generales.

Suay R., J. (1985). El principio de igualdad en la Justicia Constitucional. Madrid: Instituto de Estudios de Administración Local.

Valcárcel, A. (1994). Igualdad, idea regulativa. En El concepto de igualdad. Madrid: Editorial Pablo Iglesias.

Zoco Z., C. (2003). Igualdad en la aplicación de las normas y motivación de sentencias (Artículos 14 y 24.1 (E). Barcelona: J. M. Bosch Editor. 